\title{
Residências, disputa de projetos formativos e Serviço Social
}

\author{
Residencies, dispute of training projects and Social Work \\ Marina Monteiro de Castro e Castro* \\ Carina Bárbara de Carvalho Dornelas **
}

\begin{abstract}
Resumo: 0 artigo analisa os projetos em disputa nas políticas de saúde e educação e reflete sobre os impactos destes no desenvolvimento dos Programas de Residência Multiprofissional em Saúde à luz de uma proposta de formação que prime pela defesa e afirmação dos princípios e diretrizes do Sistema Único de Saúde (SUS), pelos valores do movimento da Reforma Sanitária brasileira e na concepção ampliada de saúde. Tem por objetivo apresentar as contradições e os desafios para a concretização das Residências enquanto espaço formativo para os assistentes sociais. Para tal, foi realizada análise de editais de Programas da região sudeste dos anos de 2018/2019 e levantamento das Instituições proponentes de Programas; além de análise das atas de reuniões da Comissão Nacional de Residência Multiprofissional e em Área profissional da saúde (CNRMS) de 2017 a 2019. Os resultados do estudo demonstram que, apesar das contradições, retrocessos e desafios enfrentados pela conjuntura atual, os Programas das Insituições Universitárias públicas estão em consonância com o debate do Serviço Social acerca da defesa de direitos, de uma política de saúde gratuita, universal e de qualidade, dos princípios do Projeto Ético Político profissional.
\end{abstract}

Palavras-chave: Residência, Serviço Social, Saúde

Abstract: The article analyzes the disputed projects in health and education policies and reflects on their impact on the development of Multiprofessional Health Residency Programs in the light of a training proposal for Residencies that strives for the defense and affirmation of the principles and guidelines of the System Unified Health System (SUS), the values of the Brazilian Sanitary Reform movement and the expanded concept of health. The objective is to present the contradictions and challenges for the implementation of Residencies as a training space for social workers. To this end, it carried out an analysis of program notices in the southeastern region of the years 2018/2019 and a survey of the institutions proposing programs; in addition to analysis of the minutes of meetings of the National Commission for Multiprofessional Residency and in the Professional Health Area (CNRMS) from 2017 to 2019.The results of the study demonstrate that, despite the contradictions, setbacks and challenges faced by the current conjuncture, the programs of the Institutions Public university students are in line with the Social Service debate on the defense of rights, on a free, universal and quality health policy, on the principles of the professional Political Ethical Project.

Keywords: Residency, Social Work, Health.

\footnotetext{
* Assistente social. Doutora em Serviço Social/UFRJ. Professora da Faculdade de Serviço Social da Universidade Federal de Juiz de Fora.

** Assistente social. Residente do Programa de Residência Multiprofissional em Saúde do Adulto- Hospital Universitário/Universidade Federal de Juiz de Fora.
} 


\section{Introdução}

A Educação Permanente, no campo das Residências em Saúde, é proposta tendo como guia os princípios do Sistema Único de Saúde (SUS) e o entendimento da formação ancorada ao próprio trabalho "que implica apreender e fortalecer o trabalho em saúde na sua dimensão criativa, valorizando o potencial educativo que dele emerge para a qualificação do atendimento às necessidades em saúde" (CLOSS, 2010, p. 24).

Dessa forma, um dos aspectos fundamentais para apropriação do debate em torno das Residências se refere às Instituições proponentes dos Programas, sua natureza e o projeto para a saúde que defende, uma vez que é essencial que as Instituições e os sujeitos que desenvolvem as Residências - gestores, tutores, docentes, preceptores e residentes, estejam alinhados a um projeto de saúde pautado nos princípios e diretrizes do SUS.

De acordo com Castro, Dornelas e Zschaber (2019), um das questões relevantes desse debate é a emissão de uma disposição legal que extinguiu a necessidade de articulação entre uma Instituição Executora e outra formadora para a oferta dos Programas - postas nas Resoluções da Comissão Nacional de Residência Multiprofissional e Área Profissional da Saúde (CNRMS) nำ/2014 e nำ1/2015. Tal dispositivo contribuiu para que Instituições, com caráter somente assistencial, assumissem a oferta dos Programas. Tal dispositivo vem sendo alvo de crítica dos Fóruns de tutores, preceptores e residentes, uma vez que a Instituição formadora é fundamental na oferta dos conteúdos teóricos e teórico-práticos dos Programas.

Amparadas nesse referencial, para aproximação da realidade da inserção do Serviço Social nos Programas de Residência, utilizamos como ponto de partida analítico os dados do relatório da pesquisa "Mapeamento das Residências em Área profissional e Serviço Social" realizado pela Associação Brasileira de Ensino em Pesquisa em Serviço Social (ABEPSS) em parceria com o Grupo de Estudos e Pesquisa dos Fundamentos do Serviço Social (GEPEFSS) da Faculdade de Serviç̧o Social da Universidade Federal de Juiz de Fora (FSS/UFJF) (ABEPSS, 2018).

Realizamos análise dos editais dos Programas da região sudeste, principal região proponente dos Programas de Residência para o Serviço Serviço Social. Optou-se pelos Programas com cenários de prática vinculados às Universidades públicas e seus Hospitais Universitários, que também se destacam na oferta de Residências, totalizando quinze (15) 
Programas. Foram levantados ainda os conteúdos requeridos pelos processos seletivos com o objetivo de identificar os elementos base para inserção nos Programas.

Apresentamos também uma análise das atas da CNRMS dos anos de 2017 a 2019 que se encontram disponíveis no site do Ministério da Saúde (BRASIL, 2019; BRASIL, 2020). A Comissão Nacional é coordenada pelo Ministério da Saúde e pelo Ministério da Educação, tendo como principais atribuições: avaliar e acreditar os Programas de Residência de acordo com os princípios e diretrizes do SUS; credenciar os Programas e as Instituições proponentes; registrar os respectivos certificados com validade nacional, de acordo com categoria e ênfase do Programa (BRASIL, 2005).

Essa reflexão foi realizada, especialmente, em diálogo com a Carta do Encontro Nacional de Residências em Saúde realizado em 2019, denominada Carta de Natal. O Encontro reúne o Fórum de preceptores, tutores, coordenadores e residentes, e tem como principal objetivo o debate político e pedagógico das Residências.

Esperamos que o presente artigo possa contribuir com os debates em torno desta modalidade de educação permanente, enquanto espaço formativo para os/as assistentes sociais, ao trazer à luz as suas contradições e os desafios para a concretização de Programas de Residência que, de fato, tenham em sua fundamentação os princípios e diretrizes do SUS.

\section{As Instituições proponentes dos Programas de Residência na região sudeste do Brasil: tensões e desafios ao Serviço Social}

Como apresentado, para a aproximação da realidade dos Programas de Residência teve-se como ponto de partida o relatório da pesquisa "Mapeamento das Residências em Área profissional e Serviço Social" realizado pela Associação Brasileira de Ensino em Pesquisa (ABEPSS), produzido a partir da análise de editais que apresentaram vagas para o Serviço Social em 2018/2019. O levantamento verificou as Instituições proponentes dos Programas, as áreas de concentração e o número de vagas disponíveis para o Serviço Social nas regiões do país.

Neste documento, é possível verificar que, na região sudeste, dos trinta e três Programas identificados no período, oito (8) são propostos pelas Universidades Federais e sete (7) por Universidades Estaduais, nove (9) são propostos por Instituições privadas ou filantrópicas; cinco (5) por Institutos ou Fundações públicas; e quatro (4) por Prefeituras ou Secretarias de Saúde municipais. Essas Instituições são responsáveis por ofertar cento e 
cinquenta e oito (158) vagas para assistentes sociais.

Em relação às Instituições proponentes dos Programas de Residência, o documento do Ministério da Saúde (BRASIL, 2005; BRASIL, 2015) que versa sobre a adesão de entes federados e Instituições à concessão de bolsas do Ministério da Saúde para Programas de Residências em área profissional da saúde, destaca que a instituição deverá, dentre outros, participar das políticas prioritárias do SUS, ter corpo docente-assistencial destinado à formação nas Residências; ter quadro de docentes e profissionais para realizarem tutoria e preceptoria; desenvolver política de educação permanente pesquisa, e ter instituída a Comissão de Residência Multiprofissional em Saúde - COREMU (BRASIL, 2005).

Diante do quadro apresentado e do aparato legal que direciona a organização dos Programas, duas questões foram guias no desenvolvimento da análise: 1. As Instituições proponentes dos Programas estão alinhadas a uma perspectiva educativa pública e ancorada em princípios democráticos e com compromisso com a população? 2. Quais os conteúdos que essas Instituições têm requerido como base para inserção nos Programas de Residência?

Estas questões são relevantes uma vez que, independente da natureza das Instituições, as Residências tem no cerne de sua composição legal o direcionamento dos princípios e diretrizes do SUS e em uma perspectiva de formação de trabalhadores que permita o exercício profissional e a reflexão teórica e teórico-prática ancorada na realidade da população brasileira.

Para responder a primeira questão, é necessário observar os dados apresentados e verificar que quinze (15) Programas são ofertados por Instituições de ensino públicas, e dezoito (18) por Instituições que têm uma forte missão assistencial ou de gestão; sendo nove (9), marcadamente privadas.

Esse cenário demonstra que não é possível analisar os Programas de Residência sem colocar em pauta a natureza das Instituições e seus compromissos com a educação permanente e com a saúde pública brasileira, já que esta é uma modalidade de formação de pós-graduação lato sensu que tem em sua proposta uma forte relação entre teoria e prática, a partir da oferta de componentes teóricos, teórico-práticos e práticos, que devem qualificar o trabalho em saúde.

Desta forma, como pensar na oferta de Programas de Residência por Instituições que não possuem em sua natureza o compromisso com a educação? Como pensar a oferta de Programas por Instituições públicas que vem sendo sucateadas e mercadorizadas ao 
longo dos anos?

O que temos visto no âmbito da educação brasileira é que a política educacional acompanha o movimento da sociedade e suas exigências produtivas voltadas para a formação de homens e mulheres aptos para produção e consumo, mas também responde às intenções da luta de classes e demandas da classe trabalhadora (PEREIRA, 2009).

Pereira (2008) frisa que apesar de o desenvolvimento educacional ser uma demanda real para a classe trabalhadora, deve-se pensar a quem ela atende sob os moldes adotados pela sociedade capitalista, uma vez que a educação é submetida às exigências do capital internacional e de sua lucratividade, a partir de investidas em Instituições privadas, sob influência do neoliberalismo. O discurso posto é de que essas Instituições prestam serviços à sociedade e formam a força de trabalho e que, por isso, requerem financiamento público não estatal. Porém, esse discurso acaba por transformar a educação em um serviço, não sendo mais vista como um bem público de responsabilidade do Estado (LIMA, 2007; PEREIRA, 2009).

No Brasil, esse processo está vinculado ao modo dependente de desenvolvimento capitalista. A política de educação brasileira:

é determinada tanto pelas necessidades de formação de força de trabalho adequada ao desenvolvimento das forças produtivas do país quanto pela requisição de intelectuais orgânicos de diversos níveis, difusores da ideologia dominante em cada período histórico(PEREIRA, 2008, p. 69).

Pereira (2008) aponta ainda que a parceria de setores empresariais com setores de pesquisa, aparece revestidas de um discurso de globalização, de novas exigências do mercado de trabalho, da dificuldade financeira do Estado para responder a essa questão, além da ideia de integração dos países e de difusão da educação como uma solução para todos os problemas da humanidade. Desta forma, a articulação com o setor privado seria uma solução para todos os déficits públicos.

Frigotto (2001) aponta que o cenário que temos é de disputa entre o projeto da educação profissional patrocinada pelos organismos internacionais versus perspectiva de emancipação da classe trabalhadora por meio da educação e acesso às políticas sociais.

Segundo o autor, a educação profissional, neste contexto, é atrelada a uma perspectiva de educação polivalente do trabalho, aliada a uma formação individualista, fragmentada e com a "mão de obra" sendo formada para o mercado de trabalho e suas exigências. Sendo assim, a função atribuída a formação passa a ser de "empregabilidade" ou 
"formação para o desemprego", uma vez que não há política de incentivo/ampliação de empregos por parte do Estado, perspectiva de carreira, etc. Este elemento também é perceptível com os egressos dos Programas de Residência, onde visualizamos dificuldades para absorção dos residentes no mercado de trabalho e na própria área da saúde (CASTRO, DORNELAS E ZSCHABER, 2019). Logo, é uma educação permanente voltada para a nova divisão do trabalho.

A perspectiva de formação que defendemos é muito diversa desta. Entendemos a necessária articulação entre as dimensões técnicas, científicas, culturais e políticas, e a educação como estratégica em meio a ofensiva do mundo globalizado. Neste projeto é central a defesa da esfera pública e também a construção de uma nova sociabilidade (FRIGOTTO, 2001). Concordamos com Meszáros (2008) ao afirmar que:

Consequentemente uma reformulação significativa da educação é inconcebível sem a correspondente transformação do quadro social no qual práticas educacionais da sociedade devem cumprir as suas vitais e historicamente importantes funções de mudança (MESZÁROS, 2008, p.25).

No Brasil, a partir do governo de Fernando Henrique Cardoso, há uma disputa clara no âmbito do ensino superior, sendo este componente essencial na contrarreforma do Estado no país. Neste âmbito, a Universidade é vista por um viés mercadológico, com a produção voltada para a lógica burguesa de manutenção do status quo e longe do interesse público da população (NASCIMENTO; OLIVEIRA, 2016).

O Plano Nacional de Educação aprovado no governo Cardoso no ano de 2001 se deu sob os moldes da modernização e aprofundou a privatização interna das Universidades, aumentou a diversificação de Instituições de ensino superior que vem sob a aparência de expansão do acesso e democratização, bem como o início do Ensino a Distância (EAD) que surge como "oferta de ensino" para os segmentos populacionais mais pauperizados (LIMA, 2007).

Vemos uma continuidade da redução de gastos com as Universidades públicas em contraposição a uma ampliação de verbas de crédito para Universidades privadas até o governo do Partido dos Trabalhadores - e que também se acirra no atual governo - com uma série de políticas de contrarreformas e parcerias público privadas, desde o âmbito do combate ao analfabetismo até o Ensino Superior (LIMA, 2007).

Apesar do discurso de defesa da educação como direito social básico e universal 
presente no governo Lula, a implementação e desenvolvimento das políticas sociais se desenvolveu permeada de contradições. Reconhecemos a ampliação das vagas nas Universidades públicas, porém esta foi acompanhada de um grande quantitativo de evasão e de investida nas fundações de direito privado em seus interiores; além do reforço do EAD .

O EAD se mostrou um espaço de expansão mercantil, em meio a uma justificativa de uma popularização do acesso, mas que se expressou como uma via de direcionamento do dinheiro público para as Instituições de Ensino Privado (IES). Dessa forma, a educação da sociedade se coloca na lógica da dominação capitalista e massificação da educação acrítica (FERRAREZ, 2016, p. 81).

Outra investida da reformulação da educação superior no governo Lula foi o Financiamento estudantil (FIES) que de 1999 a 2003 direcionou cerca de 2 bilhões de reais para Instituições privadas de ensino, além de ampliar a isenção fiscal de Instituições privadas como o Programa Universidade para Todos - PROUNI, desenvolvido sob aparência democrático-popular (LIMA, 2007).

Nesse sentido, Nascimento e Oliveira (2016) destacam que a ampliação do ensino superior teve caráter privado, favorecendo a obtenção de lucro sob a forma de isenção de impostos - através de vagas para o FIES (que endividam as famílias) e PROUNI. Entedemos que os recursos utilizados nessas estratégias deveriam ser destinados para a melhoria e ampliação das Universidades públicas ${ }^{1}$.

O que vemos é a transferência dos recursos do Estado para a iniciativa privada através da articulação público/privado, que reconfigura a forma de pensar dos sujeitos e se desdobram em privatizações no interior das Universidades públicas através, por exemplo, de cursos pagos de pós-graduação e mestrados com parcerias com o setor privado.

Assim:

\begin{abstract}
O Estado deveria investir em uma educação de qualidade para todos os brasileiros como forma de proporcionar igualdade de acesso ao mercado de trabalho, mas (desde a ditadura militar) os governos fortaleceram o repasse de verbas públicas para IES privadas como forma de garantia de acesso ao ensino superior (FERRAREZ, 2016, p. 82).
\end{abstract}

Estes fatores contribuem para a superexploração do trabalho docente e de técnicos administrativos, além da apolitização dos sujeitos, impactando diretamente na formação

\footnotetext{
${ }^{1}$ No que diz respeito à formação e a política de educação, os cursos, são submetidos a lógica do mercado a partir da concorrência entre as Instituições de Ensino Superior (IES) para se manterem no topo da lista do Exame Nacional de Estudantes (ENADE) (FERRAES, 2016, p. 81).
} 
profissional, já que muitos egressos deste sistema tem dificuldades de realizar crítica a determinadas atividades que realizam (MORAES, 2016).

A mercantilização do ensino superior brasileiro também tem impacto no Serviço Social, visto que a formação profissional na área das ciências sociais aplicadas não é descolada do movimento da totalidade.

Pereira (2017) expõe que a expansão de cursos superiores sempre foi uma pauta de luta dos movimentos da classe trabalhadora, porém a forma como esta expansão acontece nas últimas décadas tem por finalidade a lucratividade, respondendo a necessidade de ampliação do mercado e não do direito à educação e democratização do conhecimento. Este fato aponta, por exemplo, para o detrimento da formação dos assistentes sociais sob a direção da ABEPSS na primeira metade dos anos 1990.

Nota-se, de acordo com a autora, que há um significativo aumento de vagas/matrículas para o Serviço Social no governo Lula, porém a sua grande maioria é em Instituições privadas. No que tange a expansão das Universidades públicas, esta esteve ancorada no Programa de Apoio a Planos de Reestruturação e Expansão das Universidades Federais (REUNI) que se pautava na expansão do acesso às universidades públicas juntamente com uma política de assistência estudantil que, na verdade, se deu de forma extremamente frágil e com limitação na alocação de recursos. No Serviço Social, por exemplo, mais da metade dos cursos públicos foram criados neste período, sendo a maior concentração na região sudeste.

Sobre a expansão do ensino a distância, Pereira (2017) destaca que os dados expressam o predomínio do setor privado na ampliação dos cursos de Serviço Social com um crescimento de $473,58 \%$, sendo vistas 6.075 .152 matrículas no ano de 2015 . Enquanto isso, o setor público cresceu apenas 178,66\% no decorrer de 20 anos (no período de 1995 a 2015), culminando em um número de 1.952.145 matrículas.

Outro dado importante abordado pela autora é a tendência de crescimento de Instituições de ensino superior não-universitárias, já que neste mesmo período de 20 anos somam um total de 3.754.142 matrículas, aproximando-se da participação das IES universitárias, que tem um quantitativo de 4.273.155 matrículas.

[...] em 2015 as matrículas presenciais dobraram para 6.633 .545 (crescimento de $146,21 \%$, cursos presenciais), enquanto as de EaD passaram a totalizar o vertiginoso quantitativo de 1.393 .752 matrículas, com um crescimento da ordem 
de $82.762,78 \%$ (INEP, 2015). Isto é, ainda que matrículas em cursos de EaD não representem a maioria das matrículas de cursos de graduação no país, em termos absolutos, a tendência é de que, nos próximos anos - permanecendo o crescimento exponencial constatado -, a predominância seja de matrículas em cursos de graduação na modalidade de EaD (PEREIRA, 2017, p. 191).

Vemos assim que, nas duas últimas décadas, o perfil de expansão do ensino superior brasileiro tem o predomínio do setor privado, com tendência de crescimento das matrículas através do ensino à distância, sem as experiências proporcionadas pelo tripé ensino, pesquisa e extensão. Esse fato justifica-se também pela investida neoliberal no âmbito da política de educação voltada à privatização e mercadorização, como dito anteriormente.

É nesse contexto que a Educação Permanente ocupa espaço de discussão dentre os profissionais como um campo de interesse teórico, metodológico e político-ideológico. Esta é entendida como parte do processo formativo, vista para além da inserção no mercado de trabalho e sendo, sobretudo, uma formação crítica permanente, construída a partir das relações com os usuários e trabalhadores. Para tal, é necessário que se contraponha às requisições do mercado de trabalho postas pelos moldes capitalistas e que reforce uma atuação profissional com compromisso social (NASCIMENTO; OLIVEIRA, 2016).

No Serviço Social, foi ao final dos anos 2000 que se iniciou o processo de reflexão sobre a educação permanente, entendendo-a como uma possibilidade de pensar o fazer profissional por meio da reflexão crítica sobre o processo de trabalho. "Tendo em vista que a formação não se encerra na academia, a construção dos saberes sobre a ação profissional na dinâmica social exige um aprimoramento intelectual" (NASCIMENTO; OLIVEIRA, 2016, p. 154), que possibilita a melhoria na qualidade dos serviços.

São nessas circunstâncias também que as Residências se apresentam como uma estratégia de educação permanente para os trabalhadores da saúde, aliando formação e trabalho, tendo em sua estrutura organizativa Insituições responsáveis pela oferta dos conteúdos téoricos, teórico-práticos e práticos.

Neste campo, os cenários de prática dos Programas são os serviços de saúde - que também se encontram atravessados por uma ideologia privatista difundida no interior do aparelho estatal em oposição a democratização da saúde, do saber e da prática popular.

Desta forma, conforme Soares (2012), a "materialização do SUS" é contraditória devido à racionalidade hegemônica que engendrada no sistema uma série de dificultadores, como: tecnificação da saúde: novas tecnologias, equipamentos, inovação na gestão, metas; 
ampliação restrita: expansão focalizada, fragmentada, precarizada; ênfase na assistência precarizada, focalizada e emergencial: centradas no indivíduo, caráter curativo, emergencial; privatização e mercantilização da saúde pública; precarização e superexploração do trabalho na saúde pública; promoção da saúde restrita; e ampliação do tensionamento nos espaços de participação social.

Mas a defesa de estratégias formativas que qualifiquem a atuação no SUS é necessária. O SUS é um sistema que abrange a área sanitária, epidemiológica e ambiental, faz o controle sanitário de alimentos, estabelecimentos, doenças, agravos, e outras ações (CLOSS, 2010), sendo vital para a vida da população brasileira.

Essa perspectiva se articula ao entendimento de que a saúde ultrapassa a visão setorial de serviço e se articula com as mais variadas questões que envolvem a sociedade e a saúde pública, além da compreensão de que as políticas sociais estão inseridas em um campo contraditório. Por isso, nesse bojo de intensa disputa de projetos para o setor saúde, é imprescindível a presença de componentes formativos que propiciem uma reflexão crítica acerca dos serviços oferecidos - baseados no debate da reforma sanitária brasileira -, já que os profissionais serão inseridos nesses espaços como residentes.

No Serviço Social, os Programas de Residência tem se constituído como importante modalidade de formação pós-graduada na saúde, trazendo uma série de debates no campo da formação e trabalho, como: a incorporação das diretrizes formativas da profissão nesta modalidade, o questionamento a extensa carga horária dos Programas (60 horas), a garantia de conteúdos teóricos e práticos que contribuam com um trabalho na área da saúde ancorado no projeto ético-político profissional e no projeto de reforma sanitária (ABEPSS, 2018). Além disso, tem-se a complexidade das demandas apresentadas pelos usuários dos serviços de saúde que extrapolam o âmbito da doença, visto que estes sofrem diretamente com as manifestações da questão social, como a falta de emprego e renda, subemprego, habitação, analfabetismo, saneamento básico, entre outras mazelas sociais.

Assim, se torna uma desafio a construção de Programas voltados para uma ação além daquela pontual e curativa da doença, e pautada em um educação com compromisso social, tendo em vista o cenário apresentado para as políticas de educação e saúde. São os sujeitos que se movimentam por essa perspectiva formativa que serão, além de residentes, tutores e preceptores dos Programas. 


\section{Comissão Nacional de Residência Multiprofissional em Saúde: pautas, debates e disputas.}

De acordo com a Portaria Interministerial MEC/MS № 1.077, de 12 de novembro de 2009, os Programas de Residência têm duração mínima de 02 (dois) anos e carga horária de 60 horas semanais. Dessas, $80 \%$ envolvendo atividades práticas e $20 \%$ destinadas a atividades teóricas ou teórico-práticas, que englobam debates específicos de cada área de concentração profissional, mas também discussões mais amplas que dizem respeito a a saúde e a área de concentração dos Programas - entendendo a importância da integralidade do cuidado à saúde e também a elaboração de novas estratégias educativas que integrem as áreas multiprofissionais.

A referida lei, em seu artigo 14, cria a CNRMS “cuja organização e funcionamento serão disciplinados em ato conjunto dos Ministros de Estado da Educação e da Saúde" (BRASIL, 2005). Ou seja, a comissão é espaço fundamental para debate da proposta pedagógica e política das Residências. Além disso, a comissão conta com o suporte de Câmaras técnicas que tem o objetivo de contribuir na avaliação da proposição dos Programas e da pertinência de sua autorização, reconhecimento e renovação de Programas, além de contribuir no direcionamento pedagógico das áreas.

O fato é que, nos últimos governos, temos visto um esvaziamento desta comissão, devido a correlação de forças e tensões desde o processo que desencadeou o impeachment de Dilma Roussef em 2016 - que impactaram diretamente na realização das reuniões da CNRMS. Nos dados disponíveis no site oficial da Comissão Nacional, no ano de 2017 há o registro de duas atas de reuniões; em 2018 foram identificadas seis atas e, em 2019, apenas duas atas.

Por este motivo a "Carta de Natal" do IX Encontro Nacional de Residências em Saúde realizado em outubro de 2019, enfatiza a necessidade de realização das plenárias e o cumprimento do calendário de reuniões como uma questão imediata, tendo em vista a importância do acompanhamento, regulamentação e avaliação dos Programas de Residências no país.

O documento traz algumas estratégias para a retomada da Comissão Nacional e Câmaras Técnicas, como: a) Contactar o poder legislativo para articulação com câmaras municipais, conselhos de saúde, conselhos profissionais, dentre outros, para o retorno das 
atividades da Comissão Nacional de Residência Multiprofissional em Saúde (CNRMS); b) Construção de campanha pela retomada da CNRMS, que abarque ações de defesa do que são as Residências, sua importância para mudanças no SUS, seus objetivos e a importância do trabalho da CNRMS; c) Convocação do MEC e do Ministério da Saúde para reunião entre representantes dos Fóruns; d) Articulação com a Comissão Nacional de Residências Médica, para buscar parceria; e) Fomentar a elaboração de uma legislação que regulamente a CNRMS; f) Reivindicar a retomada dos Seminários Nacionais e Regionais de Residências em Saúde para construção de uma legislação, normativas que regulamentam as Residências; g) Construção de um eixo comum nos Projetos Pedagógicos dos Programas de Residências.

Traz também uma preocupação em relação às denúncias de assédio para com os/as residentes, defendendo que, para que a Residência seja efetivamente uma formação de qualidade, é fundamental que sejam combatidas todas as formas de opressão. Logo, sugere que os debates da CNRMS sejam condizentes com as vivências dos residentes, já que as denúncias por estes motivos compõem um dos assuntos que mais aparece nas atas analisadas.

A principal demanda da CNRMS, encontrada nas atas analisadas, se relaciona a apuração de denúncias que dizem respeito a irregularidades nos Programas, condições de trabalho, ocorrência de assédio moral, falta de cumprimento das normas de carga horária prática/teórica, falta de emissão de certificado de conclusão do Programa, funcionamento precário da COREMU - sem o registro em ata e acompanhamento do cumprimento das decisões acordadas -, além de denúncias de residentes substituindo a força de trabalho das Instituições.

Os processos de trancamento, afastamento e desligamento dos Programas por parte dos residentes também é um assunto importante, já que aparece em todas as plenárias. Este processo ocorre por diversos motivos, como expressos nos documentos: saúde de familiar, licença à maternidade, aprovação em concurso público e até mesmo questões de saúde do próprio residente. O que foi observado nas atas é que, até a 7ạ reunião no dia 5 de junho de 2018, não existia nenhum tipo de aparato legal que previam ações nessas situações.

Podemos identificar que foram realizadas visitas in loco com o objetivo de avaliar denúncias em relação ao funcionamento dos Programas e também referente a falta de tutores e preceptores para acompanharem os residentes em suas atividades. Como 
encaminhamento de alguns casos explicitados nas atas, foi realizado o remanejamento dos residentes para outros Programas. O Serviço social aparece nessa situação por duas vezes, sendo que o desfecho foi o deslocamento do residente para outra Programa não compatível com o de sua inserção inicial.

O debate em torno da composição da CNRMS também é um ponto bastante polêmico nas plenárias. Nas discussões é enfatizado o desequilíbrio na composição dos membros, havendo um número maior de representantes do MEC em defasagem aos números de coordenadores, preceptores, tutores e residentes. $\mathrm{O}$ argumento utilizado pela gestão federal para esta proporção é o aumento do número de Programas e de sua complexidade em relação a instâncias ministeriais. Tal discrepância na comissão já vinha sendo sinalizada desde 2013, quando no Encontro de Residências foi sinalizada a imposição da composição, e o não reconhecimento da legitimidade das deliberações e indicações políticas deste espaço (CARTA FORTALEZA, 2013).

\begin{abstract}
A CNRMS foi criada para pensar, regulamentar e deliberar sobre todas as questões das Residências em Saúde Multiprofissionais e em Área Profissional do país. A primeira composição foi regulamentada pela portaria no 45 aprovada, conjuntamente, pelos Ministérios da Saúde (MS) e da Educação (MEC). Tal Comissão foi construída coletivamente pelos diversos atores envolvidos com as Residências em Saúde (residentes, preceptores, tutores, coordenadores, gestores e trabalhadores), de modo que em sua composição todos os fóruns foram contemplados e de forma paritária, inclusive com o mesmo número de integrantes que MEC e MS. No entanto, no ano de 2009, os ministérios supracitados derrubaram arbitrariamente a portaria 45 e lançaram a portaria 1.077, para mudar a configuração, as cadeiras e os sujeitos envolvidos. Na nova configuração, passou a ser exigida lista tríplice para aprovação dos representantes de segmentos e fóruns, bem como outros movimentos organizados perderam seus representantes. Ao mesmo tempo, triplicaram-se as cadeiras do MEC e duplicaram-se as do MS. Mudou-se também a forma de organização, passando de um regime colegiado para presidencialista (CARTA FORTALEZA, 2013, p. 19).
\end{abstract}

Em 2014, o governo mudou a composição da Comissão Nacional de Residência Multiprofissional em Saúde em relação aos titulares/suplentes, por meio da Portaria Interministerial no 16, de 22 de dezembro de 2014. Agora, a CNRMS é composta por membros titulares e suplentes indicados por suas respectivas entidades e fóruns, nomeados em ato conjunto, com um mandato de 2 anos que pode ser renovado pelo mesmo período.

A composição foi definida contendo quatro membros natos do Ministério da Educação, três do Ministério da Saúde, um membro representante do Conselho Nacional de Saúde - CNS, dois representantes do Conselho Nacional de Secretários de Saúde - CONASS, dois representantes do Conselho Nacional de Secretários Municipais de Saúde - CONASEMS, 
um representante da Associação Brasileira dos Reitores das Universidades Estaduais e Municipais - ABRUEM, um representante tutor/preceptor uniprofissional, um representante tutor/preceptor multiprofissional, um representante das Associações de Ensino, um representante das entidades sindicais, um representante dos Conselhos Profissionais, um representante da Associação Nacional dos Dirigentes das Instituições Federais de Ensino Superior - ANDIFES, dois representantes dos residentes (uniprofissional e multiprofissional), um representante de Coordenadores de Residência Multiprofissional e um representante de Coordenadores de Residência Uniprofissional.

Essa composição dos membros, de acordo com as atas, não está acompanhada de nenhum tipo de capacitação interna, o que é preocupante na medida que é fundamental que a comissão tenha sujeitos que estejam alinhados com a perspectiva de defesa do SUS e da qualidade de acesso aos serviços de forma universal.

Um elemento importante que apareceu em uma das atas analisadas, foi a tentativa de um Programa ter parte da carga horária por ensino a distância. Como sinalizado, esta modalidade tem limitações formativas, já que tende a reduzir o processo reflexivo ao treinamento a partir do ensino de forma fragmentada, o que pode impedir o profissional de compreender as determinações do exercício profissional e também sua forma de intervenção na realidade. Sendo assim, a metodologia sob a qual é construída a modalidade EAD, no caso dos Programas de Residência, não propicia o encontro entre os profissionais, tão fundamental para uma formação composta de um direcionamento político-pedagógico como defendido neste trabalho.

Portanto:

\begin{abstract}
Quando falamos de educação nos remetemos à possibilidade de apropriação e reformulação de conceitos; da realização de atividades formadoras com debates, diálogos coletivos; interiorização de conceitos e apropriação da dimensão técnicooperativa: o estudante deve avaliar criticamente, a partir da construção coletiva com os outros estudantes e professores. No EAD os conteúdos são padronizados para estudo individual que por si só seriam geradores de habilidade e atitudes dos alunos, e o processo de ensino - aprendizado é mediado por recursos tecnológicos que não permite o debate e a reflexão coletiva (FERREIRA E CASTRO, 2014, p. 357).
\end{abstract}

O processo de aprendizagem através das Residências, na modalidade de pósgraduação lato sensu, tem a potencialidade de superação da distância entre ensino e serviço, com este último sendo um cenário de prática fundamental para a formação profissional a partir da vivência do trabalho. Dessa maneira, Closs (2010, p. 40) explicita que: 
As experiências criadas nos Programas de Residência indagam sobre as lacunas a serem superadas na Formação Profissional, ao mesmo tempo em que sinalizam para os limites e possibilidades de qualificação e mudança do trabalho no SUS, que devem ser alvo da Educação Permanente e da produção de conhecimentos na pósgraduação (CLOSS, 2010, p.40).

A autora esclarece que as Residências constituem uma estratégia de formação para a qualificação profissional a partir das práticas de saúde e das demandas da população usuária, de acordo com as necessidades expressas através das realidades locais e regionais sendo, por conseguinte, fundamentais para a garantia da cobertura do acesso aos serviços por parte dos usuários.

Nesse sentido, compreendemos que a efetividade da CNRMS é central para a produção de uma política nacional para as Residências em saúde, tendo em vista a sua atribuição de normatizar, assessorar e deliberar sobre as Residências.

\section{Os Processos seletivos dos Programas de Residência vinculados às Universidades Públicas}

O debate sobre os editais e organização dos processos seletivos para inserção nos Programas tem sido pauta dos Fóruns que reúne os segmentos que compõe a Residência Tutores e preceptores, coordenadores e residentes. A Carta do Encontro de Natal propõe ações de melhorias nos editais, como: inclusão de ações afirmativas; participação de todas atrizes e atores na elaboração dos editais de seleção; construção e aprovação dos editais de seleção para ingresso nos Programas de Residências nas COREMUs dos Programas de Residência, com participação de todos os segmentos; etc. (CARTA DE NATAL, 2019).

No relatório da ABEPSS (2018) é sinalizado que, na maior parte dos editais dos Programas que ofertam vagas para o Serviço Social, a forma de ingresso no Programa ocorre por meio de prova objetiva/dissertativa e análise de currículo. No que concerne aos conteúdos das provas de seleção:

grande parte dos Programas adota uma distribuição com questões com conteúdos referentes à Saúde Coletiva e área de concentração do Programa, e questões específicas do Serviço Social. Importante observar que, de uma forma geral, as referências bibliográficas estão atualizadas e englobam as legislações da área da saúde e referenciais da Saúde Coletiva. Para a temática da profissão, utilizam-se de autores de referência da área da saúde no Serviço Social, como: Bravo, Matos, Vasconcelos, Mioto; a legislação específica da área, além dos parâmetros de atuação do assistente social na política de saúde (ABEPSS, 2018, p.21). 
Nesse sentido, foi realizada análise dos referenciais teóricos presentes nos editais de propostas vinculadas à quinze (15) Universidades públicas e de Programas desenvolvidos em HU's da região sudeste do Brasil. Esta opção parte do entendimento de que as Universidades públicas tem em sua natureza o compromisso com o desenvolvimento de ensino, pesquisa e extensão que atenda as necessidades da população brasileira.

Desta forma, foi levantado no recorte das Universidades públicas da região sudeste se as referências bibliográficas estão em consonância com as temáticas da formação no âmbito do projeto ético político do Serviço Social, com o projeto do movimento de reforma sanitária e com o entendimento da saúde em seu conceito mais amplo.

Verificamos que os autores utilizados nas referências bibliográficas dos processos seletivos estão alinhados com a defesa de uma saúde pública, universal e de qualidade tendo, neste sentido, aproximação com o projeto da reforma sanitária e o projeto ético político profissional. Dentre eles, destacam-se: Bravo, Behring, Boschetti, Barroco, Mioto, lamamoto, Netto; além de referenciais das entidades da categoria, como o conjunto CFESS/CRESS

Logo, foi visto que para inserção nos Programas das Universidades públicas tem-se buscado referenciais que "defendem a valorização da formação política, garantindo que seja pontuado o compromisso político e inserção em movimentos sociais", como indicado na Carta dos Fóruns dos segmentos que compõem as Residências (CARTA DE NATAL, 2019, p. 8).

Em relação às temáticas encontradas, podemos observar que os assuntos que mais apareceram nos processos seletivos dos Programas de Residência com vagas para o Serviço Social são: políticas sociais, desigualdades e contrarreformas; Serviço Social e saúde; atuação profissional, atribuições, competências e instrumentos profissionais, e ética profissional. É dado um forte peso as legislações nacionais, assim como as que normatizam o Serviço Social. Destacam-se ainda temáticas, como: humanização, movimentos sociais, educação popular e controle social, integralidade e interdisciplinaridade, cuidado e vigilância em saúde.

Entendemos que há sempre o que avançar em relação às referências bibliográficas, porém o posicionamento e a perspectiva sob a qual os profissionais construíram os editais estão condizentes com a perspectiva defendida hegemonicamente na categoria profissional. Isso pode estar vinculado ao fato das propostas analisadas estarem vinculadas aos HU's e às Universidades públicas da região que contém cursos de Serviço Social e que tem 
historicamente buscado garantir em sua proposta formativa os valores do projeto éticopolítico profissional.

Entendemos que, no âmbito do Serviço Social, a Residência deve ser pensada no sentido de aprimorar a reflexão acerca da relação do Estado, a política de saúde e a inserção profissional nessa área, além de possibilitar a vivência de experiências teórico-práticas (CASTRO, 2013).

Nesse quadro, o assistente social precisa enxergar para além da aparência e compreender as determinações sociais existentes na realidade para intervir de forma condizente com os valores defendidos pela categoria profissional. Assim, necessita de uma qualificação para isso, tanto político-operativa como teórico-metodológica (SIMIONATTO, 2009).

Sua efetivação requer, no entanto, a consciência crítica dos profissionais e dos valores defendidos pelos mesmos, que indicam a direção do trabalho profissional. Por isso é fundamental que não exista uma apropriação apenas de forma seletiva dos componentes do Projeto Ético Político, mas uma incorporação de seus elementos e valores, especialmente, defendidos pelo Código de Ética dos/das assistentes sociais (BRITES, 2013).

É fundamental a atuação profissional articulada aos princípios expressos no Código de Ética Profissional, como: o reconhecimento da liberdade como valor ético central e das demandas políticas a ela inerentes - autonomia, emancipação e plena expansão dos indivíduos sociais; a defesa intransigente dos direitos humanos e recusa do arbítrio e do autoritarismo; Empenho na eliminação de todas as formas de preconceito, incentivando o respeito à diversidade, à participação de grupos socialmente discriminados e à discussão das diferenças; compromisso com a qualidade dos serviços prestados à população e com o aprimoramento intelectual, na perspectiva da competência profissional; entre outros (CFESS, 2012).

Neste sentido, é essencial a compreensão do trabalho do assistente social e sua relação com o Projeto Ético-Político do Serviço Social, o Código de Ética Profissional, a Reforma Sanitária no Brasil, a contrarreforma do Estado e os Programas de Residência nos quais os assistentes sociais atuam (CFESS, 2017).

Dessa forma, nos posicionamos na defesa de um SUS Universal, Público, Estatal e de qualidade com a garantia da participação social e contra quaisquer tentativas de redução do "tamanho" do SUS e do acesso ao direito à saúde, através da lógica privatista e de mercado. Assim, reiteramos o contínuo processo de estatização 
desse Sistema, nos posicionando contrariamente ao desmonte e subfinanciamento das Instituições públicas de saúde e da retirada dos projetos sociais. Repúdio total a violência contra as/os trabalhadoras/es do movimento popular, a criminalização dos movimentos sociais, a manipulação midiática, ao extermínio de militantes dos movimentos rurais e lideranças sem terra, indígenas, quilombolas e ribeirinhas, repudiamos também as medidas governamentais instituídas, e de suas propostas antidemocráticas e antipopulares, que transformam o SUS como proposta suplementar aos cuidados das/os brasileiras/os, à precarização do trabalho e dos novos modelos de gestão da saúde em nosso país (CARTA DE NATAL, 2019, p 11).

Para tal, espera-se que o debate realizado no cotidiano profissional e no decorrer das atividades dos residentes também estejam em consonância com o conteúdo programático dos processos seletivos, para que as demandas da qualificação dos projetos político-pedagógicos de cada Programa garantam uma formação política comprometida com os interesses da classe trabalhadora (CARTA DE NATAL, 2019). E por isso, no âmbito do Serviço Social:

\begin{abstract}
A ABEPSS vem defendendo que a formação para a área da saúde deve ter como objetivos a transformação das práticas profissionais e da própria organização do trabalho e estruturar-se a partir da problematização do processo de trabalho e das necessidades de saúde da população, tanto individual como coletiva. A integralidade é marcada como um eixo estruturante do processo formativo do profissional de saúde, tendo em vista que este conceito implica analisar criticamente as condições de saúde dos usuários e os elementos que estão velados nesse processo, ultrapassando as fronteiras entre o biológico, o social, o econômico e o psíquico. Desse modo, busca-se formar profissionais capacitados para trabalhar as determinações sociais do processo saúde/doença, de forma comprometida com o aprofundamento de direitos (CASTRO, 2013, p. 7).
\end{abstract}

É necessário buscar para as Residências, uma formação crítica efetiva, envolvendo uma ação que articule elementos políticos, culturais, econômicos e sociais, dentre outras esferas, imprescindíveis para a constituição histórica de uma nova direção social. Especialmente, porque os seus cenários de prática são permeados de elementos conjunturais que demandam novas respostas na intervenção profissional e que devem ser discutidas no âmbito da formação (FONSECA, 2016).

\title{
Considerações Finais
}

Apesar de todo avanço no que diz respeito aos Programas de Residência e sua estratégia de formação, CFESS (2017) aponta que existem desafios que ainda precisam ser 
superados, como a investida em uma política de formação permanente e condições de trabalho para tutoria e preceptoria; investida no debate coletivo entre as entidades representativas das profissões envolvidas; fixação dos profissionais egressos dos Programas de Residência no âmbito público, cumprindo de fato com a proposta de melhoria na qualidade dos serviços prestados pelo SUS; entre outras.

É nessa circunstância que as Residências podem se apresentar como uma estratégia de mudança nos serviços de saúde, voltada para uma ação além daquela pontual e curativa da doença, mas que se direciona à compreensão do sujeito em sua totalidade.

Para o Serviço Social, de acordo com Closs (2010), os Programas de Residência constituem um espaço de suma importância para o processo de formação profissional na área, levando em consideração a arena de disputas presentes neste campo. São de extrema importância para a formação profissional voltada para o SUS, mas também enfrentam desafios que são intensificados pela contrarreforma do Estado, refletindo na efetividade da política de saúde.

Ainda segundo a autora, é importante destacar o reconhecimento da saúde como direito social e o necessário papel do Estado para garantia de sua efetivação, sendo o/a assistente social, por conseguinte, um profissional extremamente qualificado para a atuação no serviço.

Dito isso, defendemos que a potencialidade dos Programas, no âmbito do Serviço Social, se direciona à formação de profissionais capacitados para trabalhar nas diversas determinações sociais que envolvem o processo saúde-doença - alinhados à perspectiva de defesa, garantia de acesso a direitos e nos princípios do projeto profissional, que indica uma perspectiva de atuação comprometida com os usuários e suas necessidades.

\section{Referências Bibliográficas}

ABEPSS. Relatório da pesquisa mapeamento das Residências em área profissional e Serviço Social. Juiz de Fora, 2018.2 Disponível em: <http://www.abepss.org.br/arquivos/anexos/relatorio-abepss-residencia-2018120311 50396627330.pdf>. acesso em: 19 de maio de 2020.

BRASIL. Lei no 11.129, de 30 de junho de 2005. Institui a Residência por Área Profissional em Saúde e dá outras providências. Disponível em: <http://www.planalto.gov.br/ccivil_03/_Ato2004-2006/2005/Lei/L11129.htm> Acesso em 15 de abril de 2019. 
BRASIL. Ministério da Saúde. Portaria no 1.111 de 05 de julho de 2005. Fixa normas para implementação e a execução do Programa de Bolsas para a Educação pelo Trabalho. Disponível

<http://bvsms.saude.gov.br/bvs/saudelegis/gm/2005/prt1111_05_07_2005.html>. Acesso em 26 de agosto de 2019.

BRASIL. Ministério da Educação. Atas Reuniões Plenárias da Comissão Nacional de Residência Multiprofissional em Saúde - CNRMS. 2019. Disponível em: <http://portal.mec.gov.br/component/content/article?id=71561>. Acesso em 17 de novembro de 2019.

BRASIL. Ministério da Educação. Residências em Saúde: Pró-Residência. Perguntas e Respostas frequentes - Edital no 12, de 28 de agosto de 2015. Adesão de entes federados e Instituições à concessão de bolsas do Ministério da Saúde para Programas de Residências em área profissional da Saúde, 2015. Disponível em: <http://sigresidencias.saude.gov.br/documentos/PERGUNTAS_RESPOSTAS_EDITAL_12_2015 .pdf>. acesso em 17 de novembro de 2019.

BRASIL. Ministério da Educação. Legislação Específica - Legislação vinculada aos Programas de Residência em área profissional da saúde (multiprofissional e uniprofissional). 2019. Disponível <http://portal.mec.gov.br/index.php?option=com_content\&amp;view=article\&amp;id=1250 0\%3Alegislacao-especifica\&amp;catid=247\%3Aresidencia-medica\&amp;Itemid=813>. Acesso em 23 de outubro de 2019.

BRITES, C. M. Valores, Ética direitos humanos e lutas coletivas: um debate necessário. In: FORTI, V. BRITES, C. M. (Orgs). Direitos humanos e Serviço Social: polêmicas, debates e embates. 3a edição. Rio de Janeiro: Lumen Juris, 2013.

CARTA DE NATAL. Carta de Natal. IX Encontro Nacional de Residências em Saúde. Natal, Rio Grande do Norte, 2019. Disponível em: <https://www.enrs2019.com.br/assets/pdf/CartaNatal.pdf $>$. acesso em 22 de abril de 2020.

CARTA FORTALEZA. Carta de Fortaleza. III Encontro Nacional de Residências em saúde. Fortaleza/CE, 2013.2 Disponível em: <https://drive.google.com/file/d/OByHU5ZnaoX19a3ZXalE3SmlubUU/view>. acesso em 22 de abril de 2020.

CASTRO, M. M. C. O Serviço Social nos Programas de Residência em Saúde: resultados iniciais do mapeamento da ABEPSS. Revista Temporalis, Brasília (DF), ano 13, no. 26, p. 153171, jul./dez. 2013.

CASTRO, M.M.C; DORNELAS, C. B . C; ZSCHABER, F.F. Residência multiprofissional em saúde e Serviço Social: concepções, tendências e perspectivas. Revista Libertas. Juiz de Fora, FSS/UFJF, v. 09, n2, 460-481, 2019.

CFESS. Código de ética do/a assistente social. Lei 8.662/93 de regulamentação da profissão. - 10å. ed. rev. e atual. - [Brasília]: Conselho Federal de Serviço Social, [2012]. Disponível em: <http://www.cfess.org.br/arquivos/CEP_CFESS-SITE.pdf>. acesso em 13 de abril de 2019. 
CFESS. Residência em Saúde e Serviço Social - subsídios para a reflexão. Brasília. 2017. Disponível em: <http://www.cfess.org.br/arquivos/CFESSBrochuraResidenciaSaude.pdf>. acesso em 15 de abril de 2019.

CLOSS, T. T. O Serviço Social nas Residências Multiprofissionais em Saúde na Atenção Básica: formação para a integralidade? Dissertação (Mestrado) - Programa de Pós- Graduação em Serviço Social, Pontifícia Universidade Católica do Rio Grande do Sul, Porto Alegre. 2010. Disponível em: <http://tede2.pucrs.br/tede2/bitstream/tede/473/1/426179.pdf>. Acesso em 04 de maio de 2019.

FERRAREZ, C. S. Mercantilização da Educação Superior no Brasil e formação profissional. In: ABEPSS. Formação profissional e Serviço Social. Revista Temporalis, Brasília (DF), ano 16, $n$. 31, jan/jun, p. 79-103, 2016.

FERREIRA; A. M; CASTRO, M. M. Educação Superior e Ensino à distância: desafios para a formação profissional do Serviço Social. Emancipação, Ponta Grossa, v.14, n2, p. 349-360, 2014.

FONSECA, C. C. O projeto de formação do Serviço Social e as inflexões do pensamento pósmoderno. In: ABEPSS. Formação profissional e Serviço Social. Revista Temporalis, Brasília (DF), ano 16, n. 31, jan/jun, p. 189-218, 2016.

FRIGOTTO, Gaudêncio. Educação e Trabalho: bases para debater a educação Profissional Emancipadora. Perspectiva, Florianópolis, v.19, n. 1, p. 71-87, 2001.

LIMA, K. Contra-reforma na Educação Superior: de FHC a Lula. São Paulo: Xamã, 2007.

MÉSZÁROS, I. A Educação para além do capital. 2a edição. São Paulo: Boitempo, 2008.

MORAES, C. A. S. Os desafios do novo século à formação em Serviço Social. In: ABEPSS. Formação profissional e Serviço Social. Revista Temporalis, Brasília (DF), ano 16, n. 31, jan/jun, p. 105-131, 2016.

NASCIMENTO, C. C. S; OLIVEIRA, C. M. Educação Permanente e Serviço Social: apontamentos sobre a formação profissional. Revista Temporalis, Brasília (DF), ano 16, n. 31, jan/jun, p. 133-165, 2016.

PEREIRA, L. D. Educação e Serviço Social: do confessionalismo ao empresariamento da formação profissional.São Paulo: Xamã, 2008.

PEREIRA, L. D. Expansão dos cursos públicos de Serviço Social entre os anos de 2003 e 2016: desafios para a formação profissional. Revista Katalysis, Florianópolis, v.21. n.1, p.189-199, 2017.

PEREIRA, L. D. Mercantilização do ensino superior, educação a distância e Serviço Social. Revista Katalysis. Florianópolis: v.12. n.2, p.268-277, 2009.

SIMIONATTO, I. As expressões ideoculturais da crise capitalista e sua influência teóricopolítica. In: CFESS/ABEPSS. Serviço Social: direitos sociais e competências profissionais. Brasília, 2009. 
SOARES, R. C. A racionalidade da contrarreforma na política de saúde e o Serviço Social. In: BRAVO, M. I; MENEZES, J.S.B. M. Saúde, Serviço Social, Movimentos Sociais e Conselhos. São Paulo: Editora Cortez, 2012, p.85-108

Recebido em: 19.05.2020 Aceito em: 08.10.2020 